\title{
The genetic origin and architecture of sex determination
}

Tisham De ${ }^{1 *}$

\section{Department of Life Sciences, Imperial College London, UK}

*Corresponding author and lead contact

Dr Tisham De, email: tisham.de08@imperial.ac.uk

\begin{abstract}
Here, I demonstrate that sex determination and sexual dimorphism across tree of life are deeply related to polyamine biochemistry in cells, especially to the synteny of genes: [SAT1-NR0B1], [SAT2-SHBG] and DMRT1. This synteny was found to be most distinct in mammals. Further, the common protein domain of SAT1 and SAT2 - PF00583 was shown to be present in the genome of the last universal common ancestor (LUCA). Protein domain-domain interaction analysis of LUCA's genes suggests the possibility that LUCA had developed an immune defence against viruses. This domain-domain interaction analysis is the first scientific evidence indicating that viruses existed at least 3.5 billions years ago and probably co-existed with LUCA on early Hadean Earth.
\end{abstract}

Weiss et al $2016^{1}$ used phylogenetic approaches to infer the physiology and habitat of the last universal common ancestor (LUCA) and reported 355 genes and its protein domains. One of LUCA's domain PF00583 maps to two human genes SAT1 and SAT2. Here, I demonstrate that in humans and all mammals, 1) SAT2 always occurs on autosomes and lies in very close proximity to SHBG (sex hormone binding globulin), 2) SAT1 always occurs on X chromosome and lies near NR0B1 (DAX1 protein) and 3) DMRT1 is always on a different but autosomal chromosome (Figure 1, Supplementary figure 1) (Supplementary table 1, Supplementary table 2). This synteny or genetic linkage suggests evolutionarily converged co-regulation of genes. Further, SAT1 and NROB1 tend to be located at a fixed distance of $\sim 6-7$ mega base pairs (Mbps) in the genomes of all mammals (Humans $=6.5 \mathrm{Mbps}$, Horse $=5.6$ Mbps, Blue Whale=6.9 Mbps), indicating that they have conserved long range interactions. SAT2 and SHBG on the other hand are usually located quite close to each other but with opposite orientation, suggesting transcriptional co-regulation. Some notable exceptions to these broad patterns were 
Petromyzon marinus (sea lamprey), Asterias rubens (common starfish) and some birds and animals endemic to the Australian continent.

Of note, in almost all human cancers the synteny of somatic structural variations of these genes is highly correlated and conserved (Figure 2, Supplementary figure 2), thus confirming and validating the common evolutionary trajectories observed in different species. The fact that this correlation in cancer genomes is mainly seen as structural variations (deletion and duplications) and not as somatic point mutations ${ }^{2}$ strongly indicates that the function of these genes and its effect on cellular phenotype (e.g. sex) is based on gene dosage and the concentrations of its protein products. These correlated somatic mutations perhaps define unique cellular states based on metabolism and homeostatis. Gene expression analysis from public databases ${ }^{3,4}$ further shows that SAT1 or spermidine biosynthesis related genes and pathways are universally expressed in almost all cell types (Supplementary video 1) across all species, where as SAT2, SHBG, NR0B1 and DMRT1 are very tissues specific, and likely to be influenced by other factors not known at the moment. Of note, chromosome Xp21.2-Xp22.1 duplications containing SAT1 and NR0B1 was earlier reported in sex reversed human individuals (male to female with normal 46, XY karyotype $)^{5-7}$. Polyamines were also found to be involved in ethrel based sex reveral of cucumbers (Cucumis sativus L.) ${ }^{8}$. Based on current literature on polyamines (SAT1 and SAT2), NR0B1, SHBG and DMRT1, it appears that these genes are functionally connected through their common role in male testis formation by sertoli cells ${ }^{9,10}$. In birds, SAT1 and NR0B1 are always autosomal and co-located, SAT2 and SHBG are absent from the genome and DMRT1 always lie on the sex chromosome Z. In fish (which may not have distinct sex detemination system), amphibians and reptiles, most of these genes including SHBG are present (unlike birds), but with depleted events of co-location and usually do not occur on the same chromosome. Platypus (Ornithorhynchus anatinus) is the only species where SAT2, SHBG and DMRT1 were found to be co-located close to each other on the same chromosome. Further, taking into account suggestive evidence from invertebrates ${ }^{11,12}$, plants $^{13-18}$, bacteria, archaea ${ }^{19-21}$ and viruses ${ }^{22,23}$, one may conclude that polyamines and its regulation are likely to be a universal and important component of the polygenic architecture of sex determination and sexual dimorphism across tree of life on Earth. An 
explanation for such a fundamental effect of polyamines like spermidine is perhaps because of its high positive charge $(+3)$ which makes it a vital interaction partner for negatively charged nucleotides like DNA and RNA in the nucleus of the cell ${ }^{24}$.

Protein domain-domain interaction analysis ${ }^{25,26}$ offers an alternative to protein-protein interaction analysis. Here, I have reported the protein domain-domain interaction analysis of the 355 domains reported by Weiss et al. 2016. Reactome ${ }^{27}$ pathway analysis (Homo sapiens) of the superset of protein domains obtained from this analysis shows strong enrichment for immune related genes and pathways. These observations indicate that LUCA's protein domains and its interaction partners were perhaps part of larger biological pathways related to primitive immune defense against viruses (Figure 3, Supplementary table 3).

\section{AUTHOR CONTRIBUTIONS}

T.D Involved in study design, performed analysis and wrote the manuscript.

\section{DECLARATION OF INTERESTS}

No external or financial interests to be declared.

\section{MAIN FIGURE TITLES AND LEGENDS}

Figure 1. New taxonomy of tree of life based on polyamines.

Figure 2. Synteny of [SAT1-NR0B1], [SAT2-SHBG] and DMRT1 in pan-cancer and breast cancer studies.

Figure 3. An overview of the evolution of life from LUCA to Homo Sapiens.

\section{SUPPLEMENTAL TABLE TITLES}

Supplementary table 1. Synteny results from UCSC genome browser

Supplementary table 2. Synteny results from the Ensembl genome browser. 
Supplementary table 3. Reactome pathway results for LUCA's domains and its interaction partners.

\section{SUPPLEMENTAL FIGURES}

Supplementary figure 1. Gene expression results form GTEx

Supplementary figure 2. Synteny of [SAT1-NR0B1], [SAT2-SHBG] and DMRT1 in various cancer studies.

Supplementary video. Summary of single cell gene expression data ( $\mathrm{N}=229$, experiments) for SAT1 in various species. Url: https://www.ebi.ac.uk/gxa/sc/home

\section{References}

1. Weiss, M. C. et al. The physiology and habitat of the last universal common ancestor. Nat Microbiol 1, 16116 (2016).

2. De, T. et al. Signatures of TSPAN8 variants associated with human metabolic regulation and diseases. iScience 24, 102893 (2021).

3. Papatheodorou, I. et al. Expression Atlas update: from tissues to single cells. Nucleic Acids Res. 48, D77-D83 (2020).

4. GTEx Consortium. The Genotype-Tissue Expression (GTEx) project. Nat. Genet. 45, 580-585 (2013).

5. Bardoni, B. et al. A dosage sensitive locus at chromosome $\mathrm{Xp} 21$ is involved in male to female sex reversal. Nat. Genet. 7, 497-501 (1994).

6. Bouma, G. J. et al. Gonadal sex reversal in mutant Dax1 XY mice: a failure to upregulate Sox9 in pre-Sertoli cells. Development 132, 3045-3054 (2005).

7. Swain, A., Narvaez, V., Burgoyne, P., Camerino, G. \& Lovell-Badge, R. Dax1 antagonizes Sry action in mammalian sex determination. Nature 391, 761-767 (1998).

8. Wang, Q. et al. Molecular cloning and expression analysis of spermidine synthase gene during sex 
reversal induced by Ethrel in cucumber (Cucumis sativus L.). Plant Sci. 169, 768-775 (2005).

9. Swift, T. A. \& Dias, J. A. Stimulation of polyamine biosynthesis by follicle-stimulating hormone in serum-free cultures of rat Sertoli cells. Endocrinology 120, 394-400 (1987).

10. Ferguson-Smith, M. The evolution of sex chromosomes and sex determination in vertebrates and the key role of DMRT1. Sex Dev. 1, 2-11 (2007).

11. Wang, Y. et al. Identification and Characterization of the DMRT11E Gene in the Oriental River Prawn Macrobrachium nipponense. Int. J. Mol. Sci. 20, (2019).

12. Kasahara, R., Yuzawa, T., Fujii, T., Aoki, F. \& Suzuki, M. G. dmrt11E ortholog is a crucial factor for oogenesis of the domesticated silkworm, Bombyx mori. Insect Biochem. Mol. Biol. 129, 103517 (2021).

13. Luo, J. et al. A novel polyamine acyltransferase responsible for the accumulation of spermidine conjugates in Arabidopsis seed. Plant Cell 21, 318-333 (2009).

14. Wang, D. et al. Effect of Exogenous Nitro Oxide on Chilling Tolerance, Polyamine, Proline, and $\gamma$-Aminobutyric Acid in Bamboo Shoots (Phyllostachys praecox f. prevernalis). J. Agric. Food Chem. 65, 5607-5613 (2017).

15. Chen, D., Shao, Q., Yin, L., Younis, A. \& Zheng, B. Polyamine Function in Plants: Metabolism, Regulation on Development, and Roles in Abiotic Stress Responses. Front. Plant Sci. 9, 1945 (2018).

16. Bueno, M. \& Cordovilla, M.-P. Polyamines in Halophytes. Front. Plant Sci. 10, 439 (2019).

17. Kakkar, R. K. \& Rai, V. K. Plant polyamines in flowering and fruit ripening. Phytochemistry 33, 1281-1288 (1993).

18. Aloisi, I., Cai, G., Serafini-Fracassini, D. \& Del Duca, S. Polyamines in Pollen: From Microsporogenesis to Fertilization. Front. Plant Sci. 7, 155 (2016).

19. Michael, A. J. Polyamine function in archaea and bacteria. J. Biol. Chem. 293, 18693-18701 (2018).

20. Becerra-Rivera, V. A. \& Dunn, M. F. Polyamine biosynthesis and biological roles in rhizobia. FEMS Microbiol. Lett. 366, (2019). 
21. Michael, A. J. Polyamines in Eukaryotes, Bacteria, and Archaea. J. Biol. Chem. 291, 14896-14903 (2016).

22. Mounce, B. C. et al. Inhibition of Polyamine Biosynthesis Is a Broad-Spectrum Strategy against RNA Viruses. J. Virol. 90, 9683-9692 (2016).

23. Mounce, B. C., Olsen, M. E., Vignuzzi, M. \& Connor, J. H. Polyamines and their role in virus infection. Microbiol. Mol. Biol. Rev. 81, (2017).

24. Zhang, R. \& Shklovskii, B. I. The pulling force of a single DNA molecule condensed by spermidine. Physica A: Statistical Mechanics and its Applications 349, 563-570 (2005).

25. Mosca, R., Céol, A., Stein, A., Olivella, R. \& Aloy, P. 3did: a catalog of domain-based interactions of known three-dimensional structure. Nucleic Acids Res. 42, D374-9 (2014).

26. Kim, Y., Min, B. \& Yi, G.-S. IDDI: The Integrated Domain-Domain Interaction Analysis System. in 2011 IEEE International Conference on Bioinformatics and Biomedicine 520-525 (ieeexplore.ieee.org, 2011).

27. Jassal, B. et al. The reactome pathway knowledgebase. Nucleic Acids Res. 48, D498-D503 (2020). 
STUDY OF ORIGII

PROFILED FOR CNV

PROFLED FOR POINT MUTATION

PROFLED FOR
STRUCTURAL VARIATION

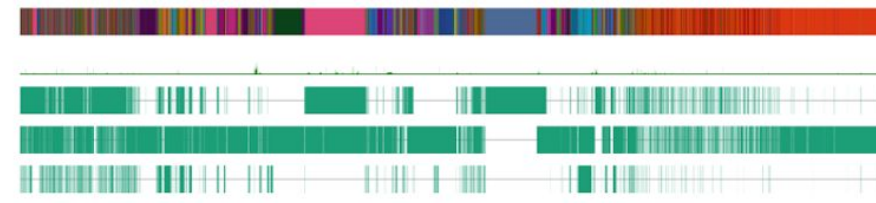

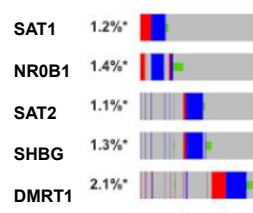

DMRT1 $2.1 \%$

his

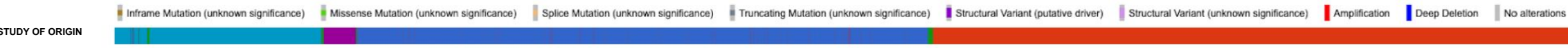

SAMPLES PER PATIENT

PROFLED FOR CNV
PROFLED FOR POINT MUTA

PROFILED FOR

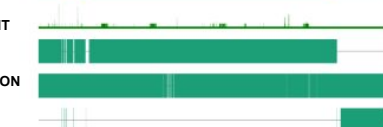

\begin{tabular}{ll|} 
SAT1 & $1 \% *$ \\
NR0B1 & $1.1 \% *$ \\
SAT2 & $0.3 \% *$ \\
SHBG & $0.4 \% *$ \\
\hline DMRT1 & $0.7 \%$
\end{tabular}

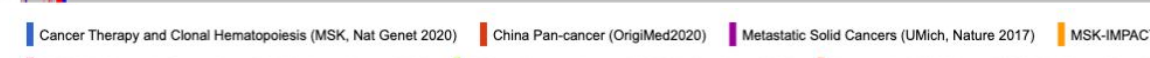

| suMMiT - Neratinib Basket Study (Mulb-Institute, Nature 2018) || TMB and Immunotherapy (MSKCC, Nat Genet 2019) | Tumors with TRK fusions (MSK, Clin Cancer Res 2020)

stror of orege $\quad$ | SAMPLES PER PATIENT

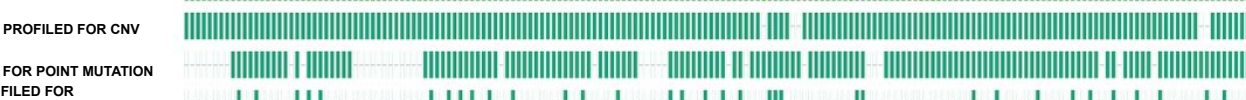

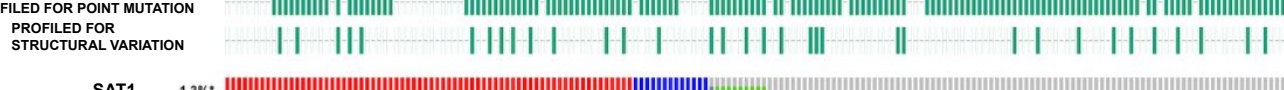

SAT1

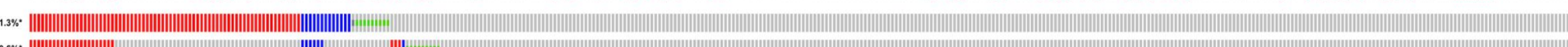

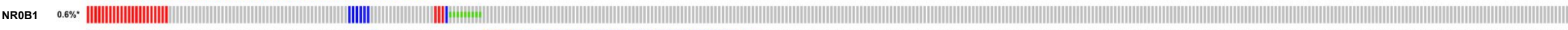

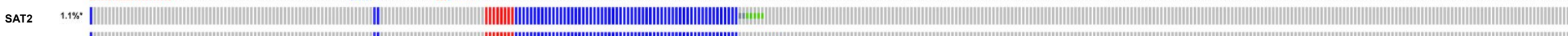

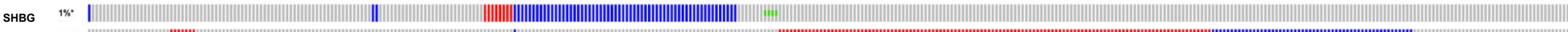

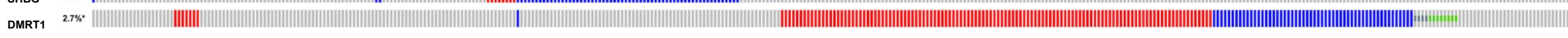

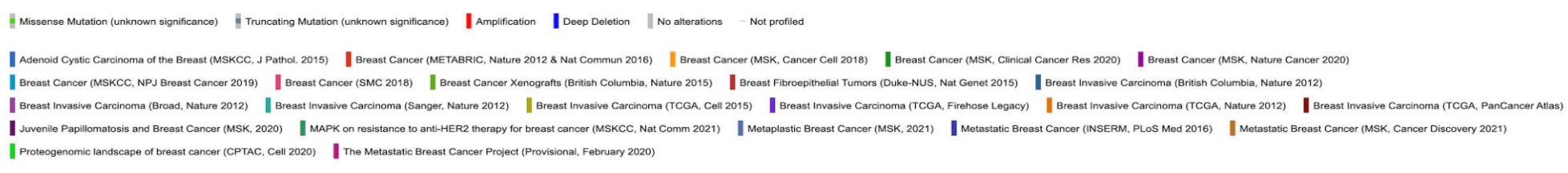

Figure 2. Synteny of [SAT1-NROB1], [SAT2-SHBG] and DMRT1 in pan-cancer and breast cancer studies. 
4-3.5 billion years

ago (BYA)

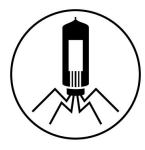

3.5 BYA

2 BYA

2-2.5 BYA

0.5-0.27 BYA

0.37-0.05 BYA

0.05 BYA PRESENT

\section{First universal common ancestor}

First RNA translated into a protein by the ribosome, most likely in a RNA and 'metabolism first' world. Most stable nucleotides and amino acids ( $L$ and $D$ forms) selected.

\section{Last universal common ancestor}

We inferred the physiology and habitat of the last universal common ancestor (LUCA) through phylogenetic analysis. Protein domain interaction analysis indicates possible existence of viruses with LUCA.

\section{First eukaryote}

An Archaea was engulfed by a bacteria which subsequently led to a symbiotic relationship with the host. This led to the emergence of the first mitochondria in a cell.

\section{Origin of sexual reproduction}

Simple multicellular organisms emerge with perception based on simple chemotaxis and chemical sensing. This leads to the formation of the first sexually reproducing microorganisms 2 billion years ago.

\section{Cambrian explosion}

Fluctuating oxygen concentrations affect body size of animals and insects. Vision and brain development lead to consciousness and emergence of predator-prey relationships -Darwinian evolution begins.

Origin of marine fish and animals

Darwinian evolution lead to the emergence of first vertebrates and jawed fish.

\section{First plants on land}

Cyanobacteria from precambrian era evolve into flowering and seed producing plants on land.

\section{Origin of dinosaurs and then birds}

Dinosaurs emerge and then get extinct. Some dinosaurs survive and probably evolve into birds.

\section{Origin of mammals and homo sapiens}

Multicellular, eukaryotic and sexually dimorphic mammals arise and flourish. Human evolution leads to climate change which starts new evolutionary events in animals and plants. Eg diminishing nutrients in plant based food or elongated beaks in birds.

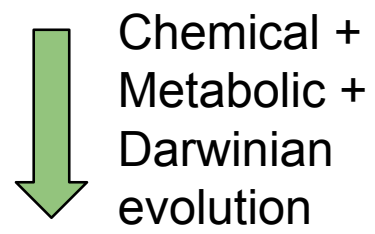

\section{Chemical evolution}

Chemical + Metabolic + evolution

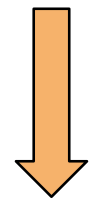

Chemical + Metabolic + Darwinian Evolution+ Climate change 


\section{SAT1}

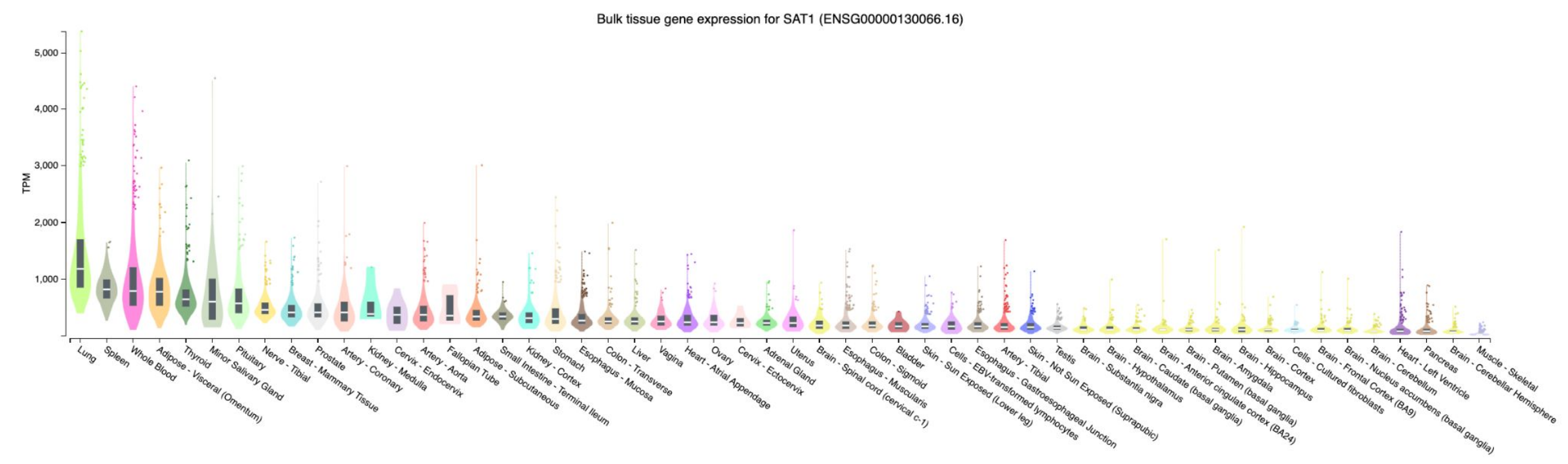




\section{NR0B1}

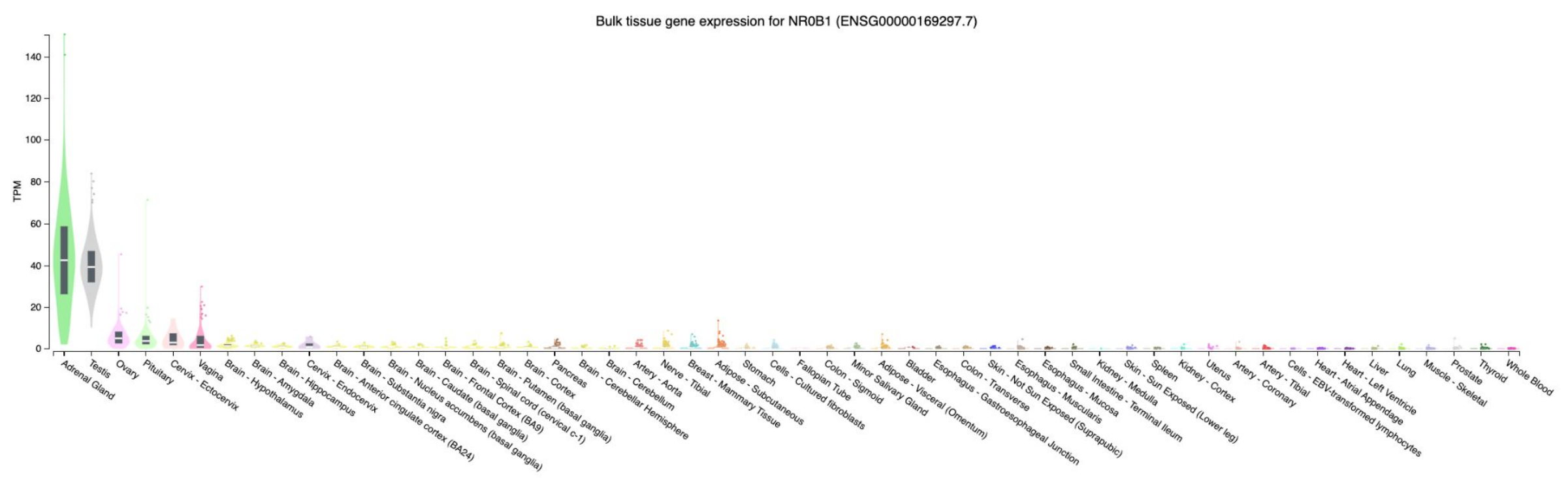




\section{SAT2}

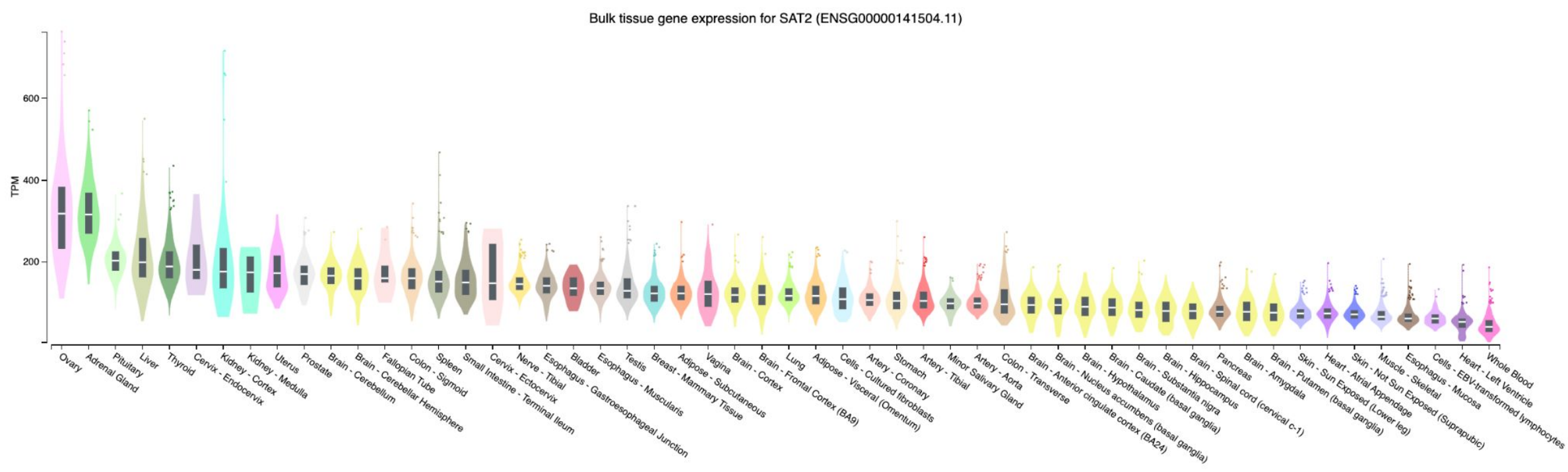




\section{SHBG}

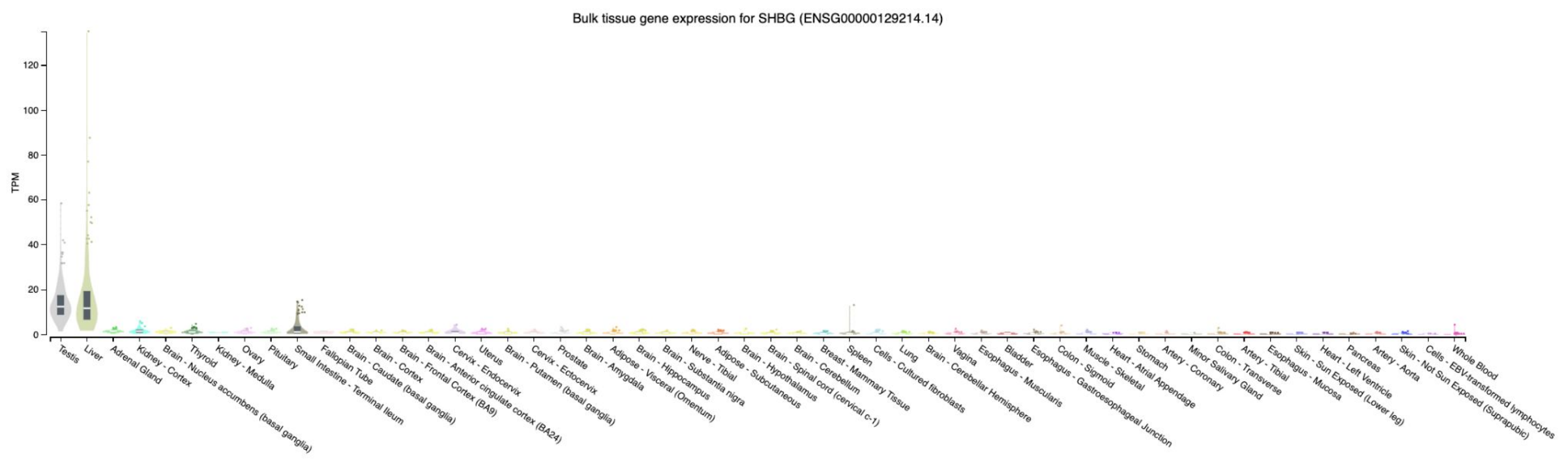




\section{DMRT1}

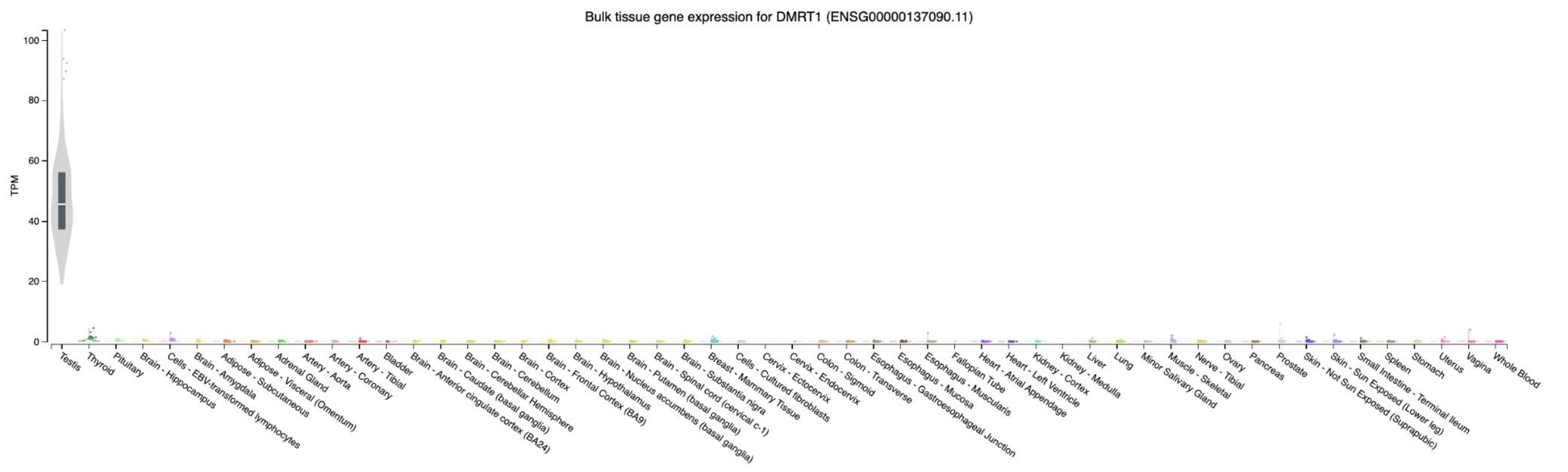




\section{SRY}

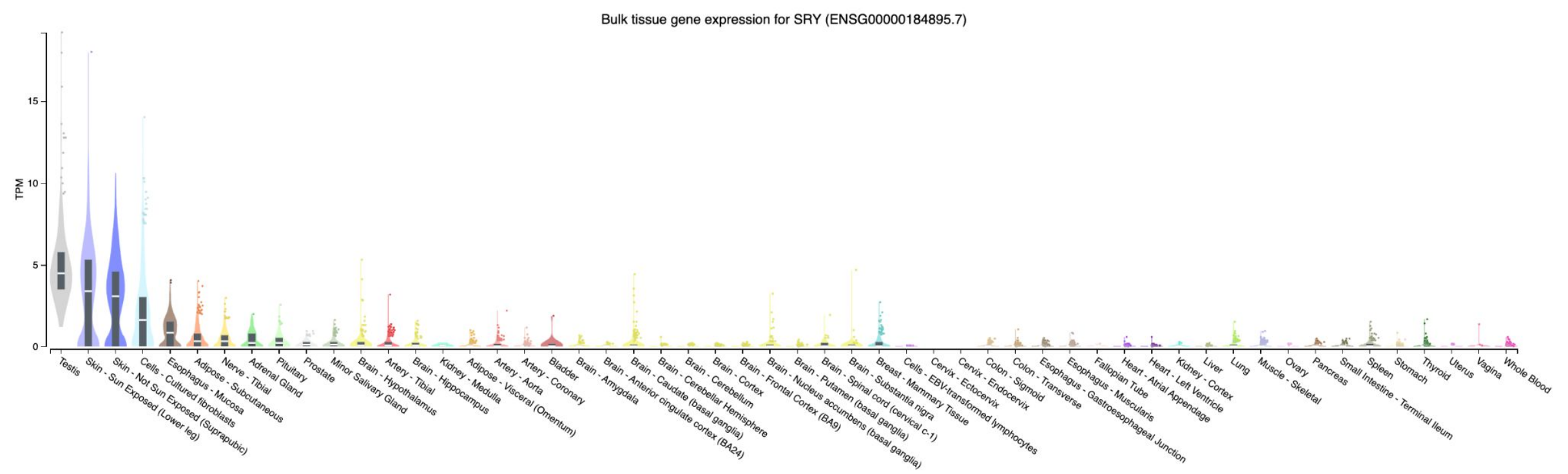




\section{ADRENAL CANCER}

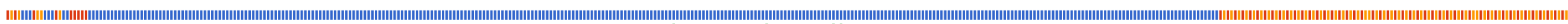

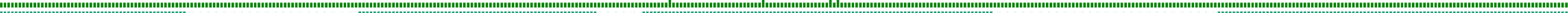

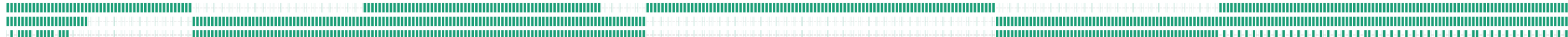

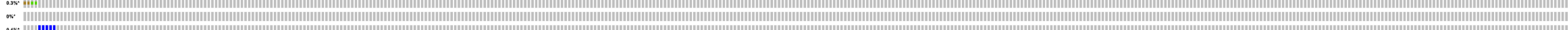

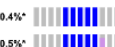

oss

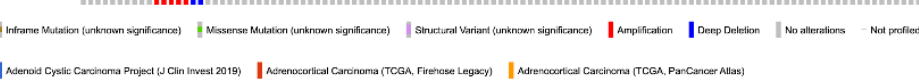




\section{BLADDER CANCER}

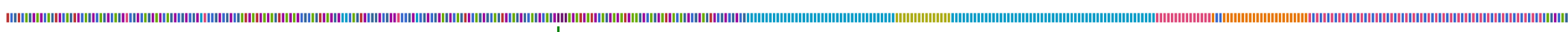

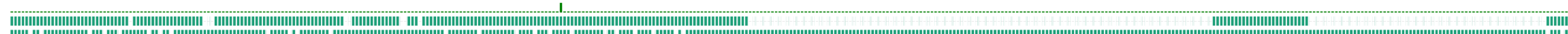

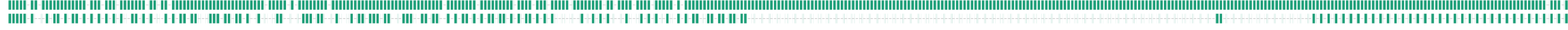

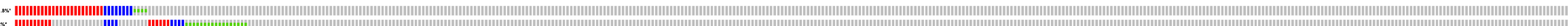

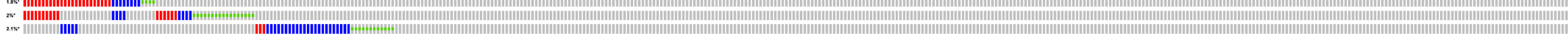

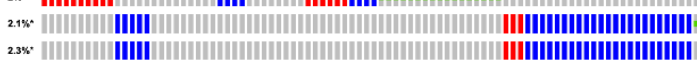

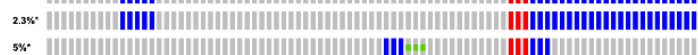

-

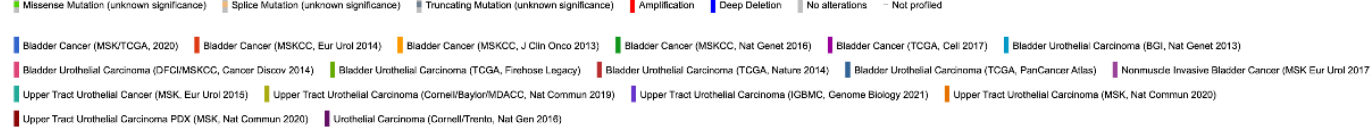

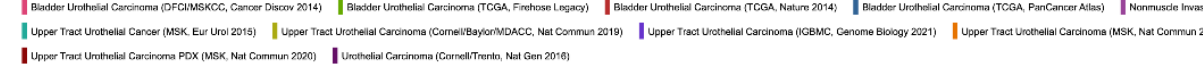

$\triangle 12$

=

Inom $-\infty$ 


\section{BOWEL CANCER}

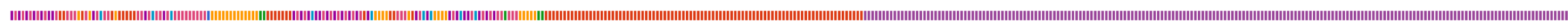

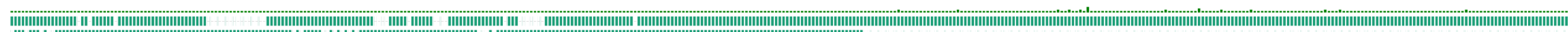

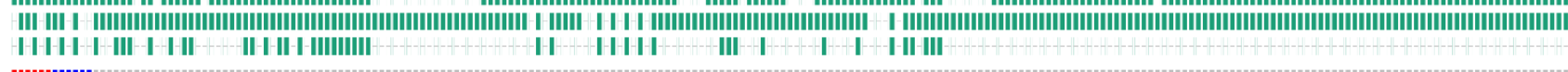
(1)

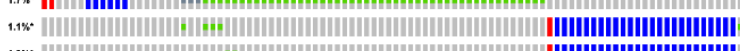

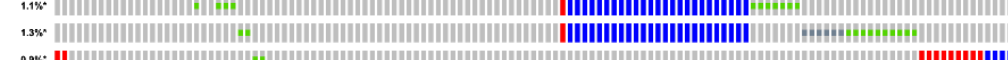

...

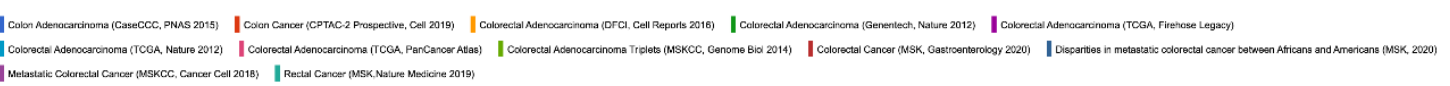

$-$

$\checkmark 4$

rom - - no

Ires - n 


\section{BREAST CANCER}

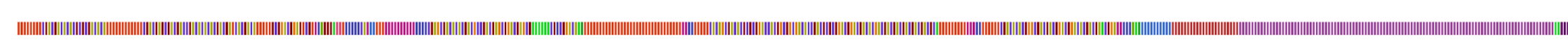

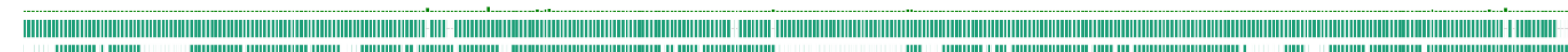

II IIIIII)

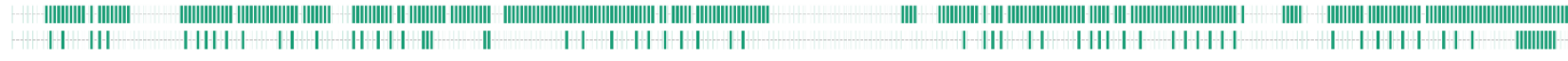

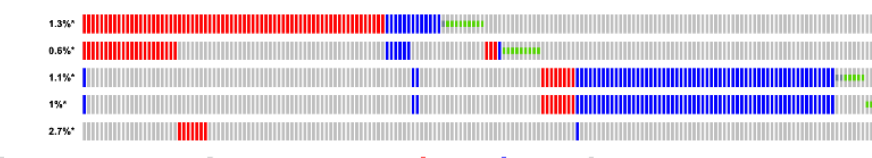

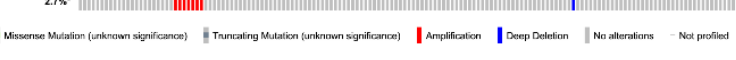

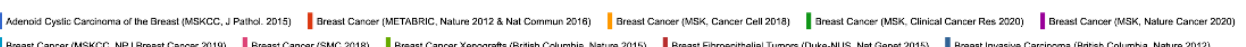

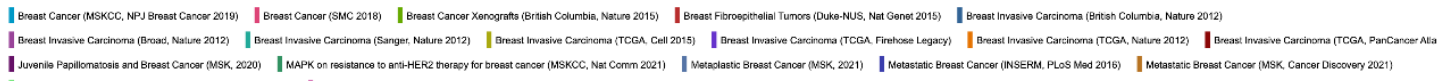

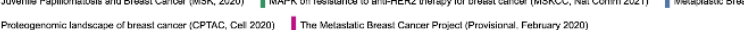

-

Im:

Ires - ne 


\section{CELL LINES}

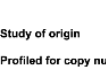

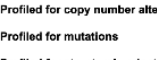

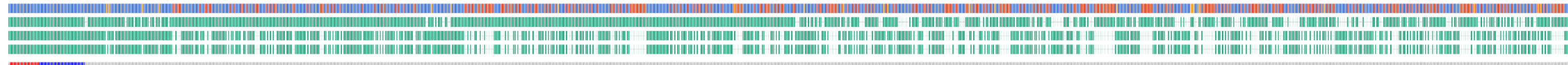
sw.

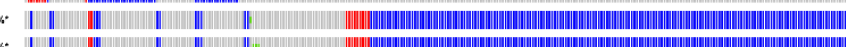

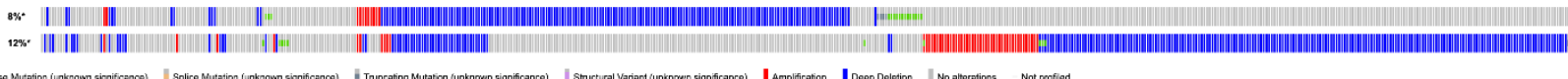

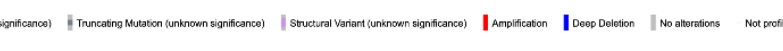

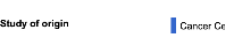

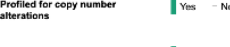

Inos no 


\section{CERVIX CANCER}

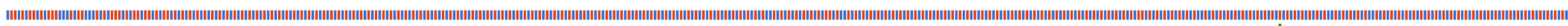

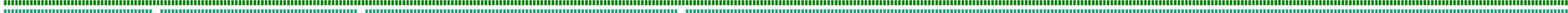

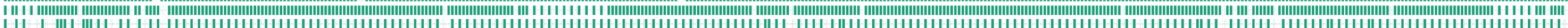

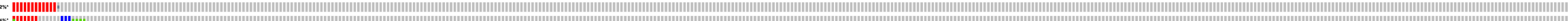

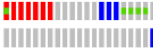

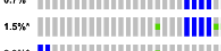

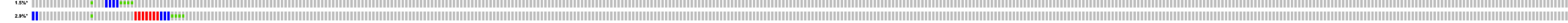

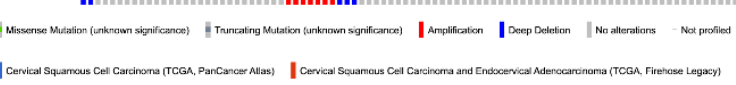

$4^{2}$

trom $-m$

Ine - - no 


\section{CNS BRAIN CANCER}

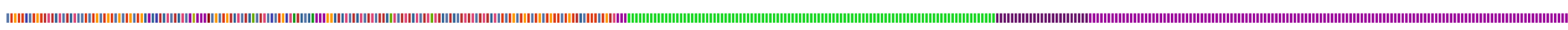

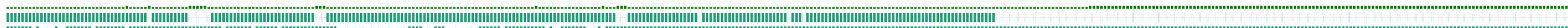

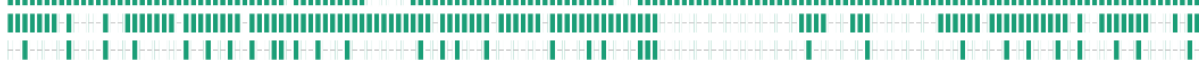

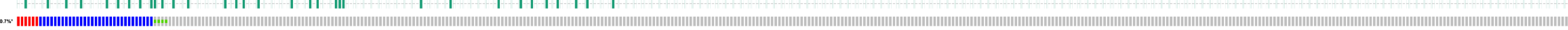

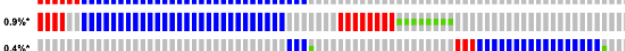

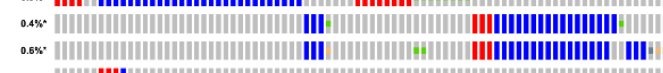

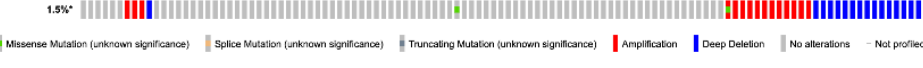

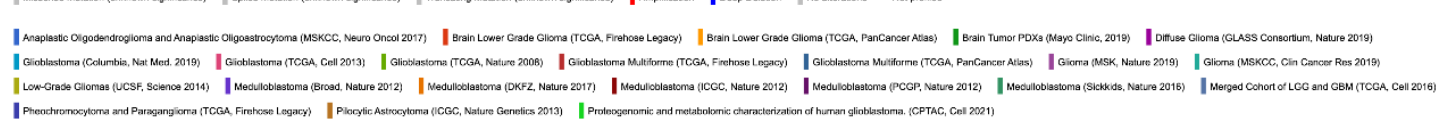

samples per Patient

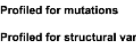

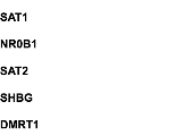




\section{HEAD AND NECK CANCER}

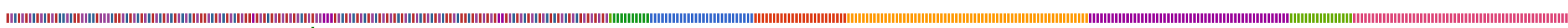
"

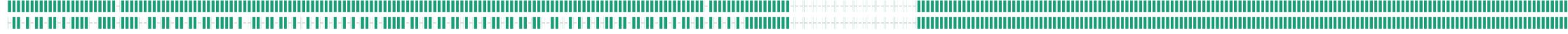

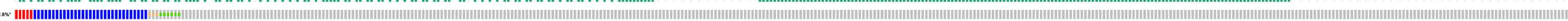

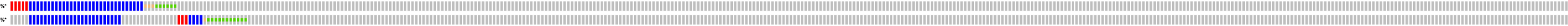

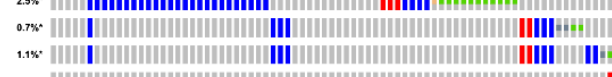

(1)

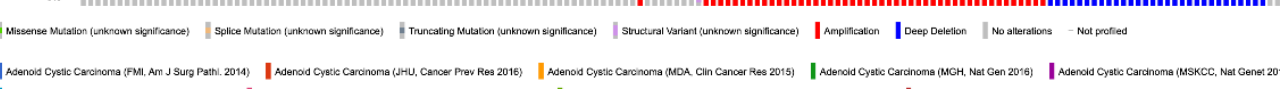

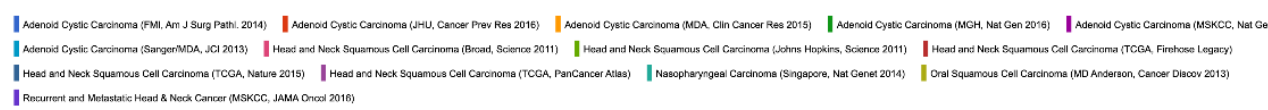

$-4$

yes - No

$I m-n$

Stsydof oritin

Protedet tor mutatit

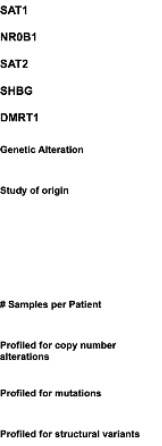




\section{KIDNEY CANCER}

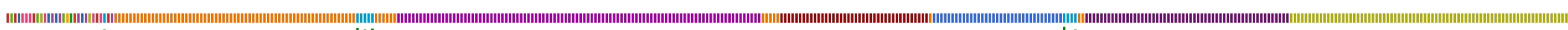

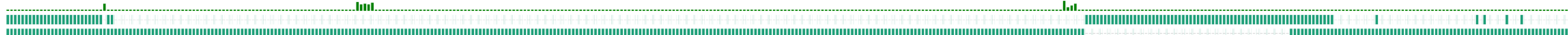

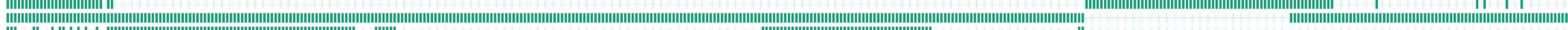

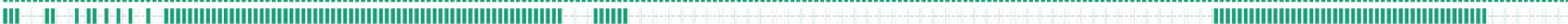

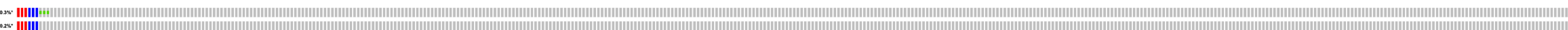

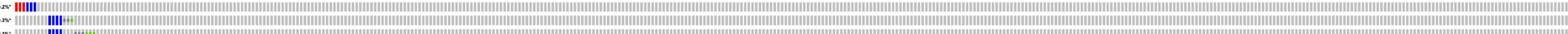

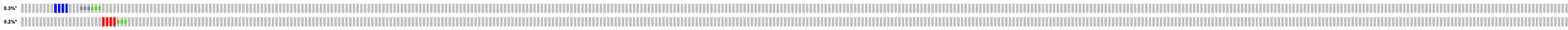

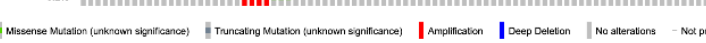

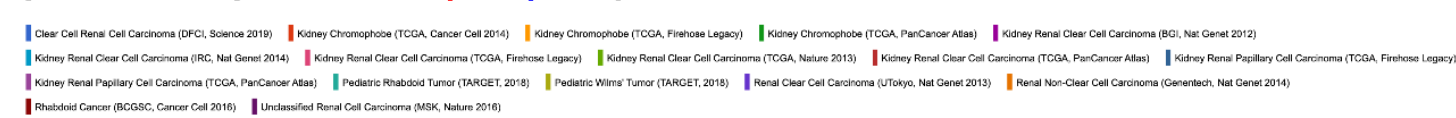

-

Ires - ne

Inom - - o

Tres -1 


\section{LIVER CANCER}

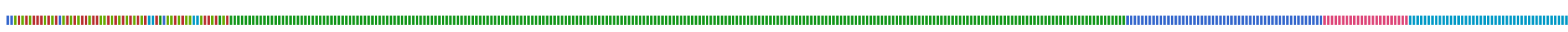

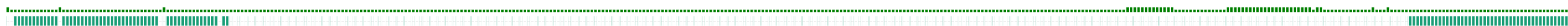

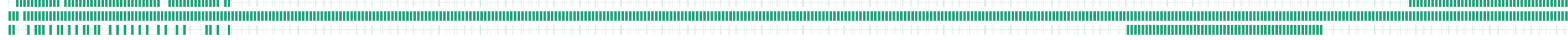

:

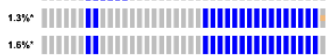

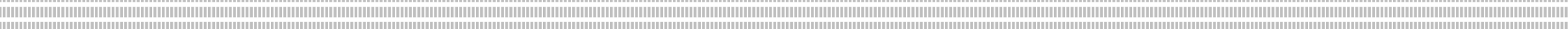

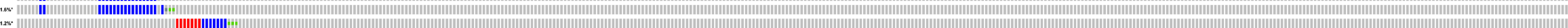

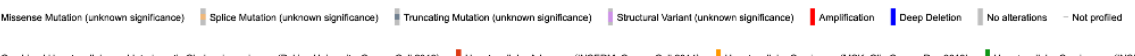

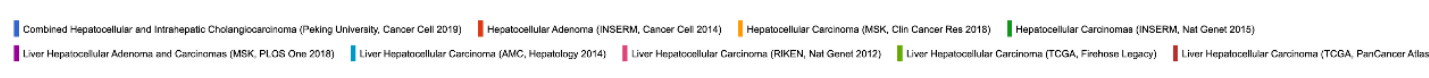

4

Ins - no

Ine - -

Inse - - 


\section{LUNG CANCER}

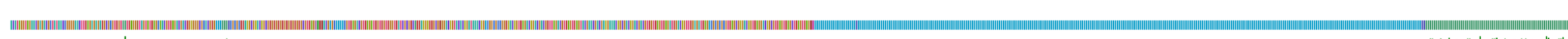

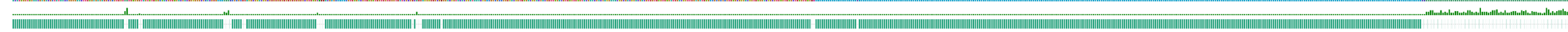

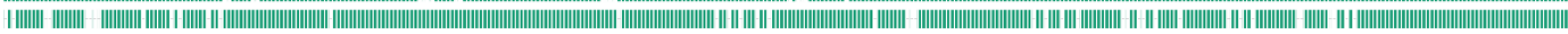

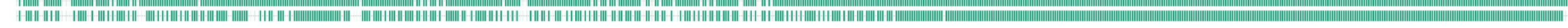

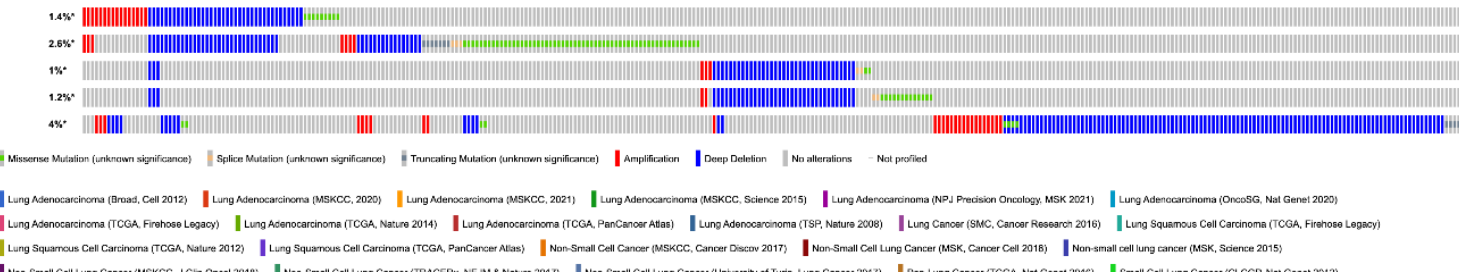

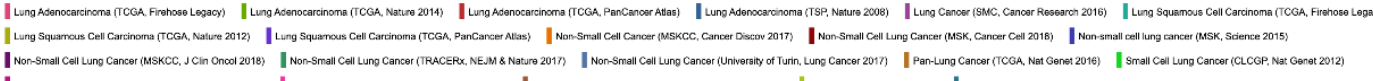

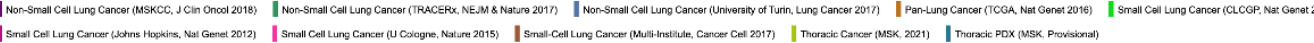

$-$

.

Iros -1

Irom - - in 


\section{LYMPHOID CANCER}

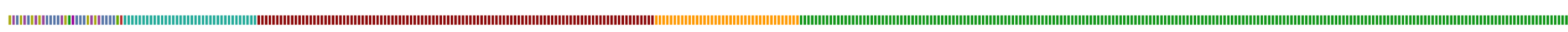
-

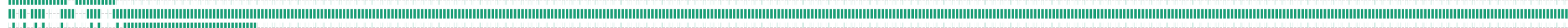

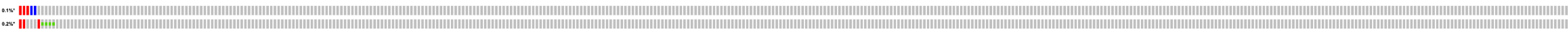

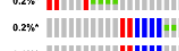

о.

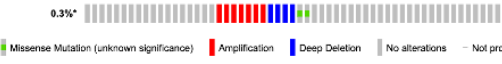
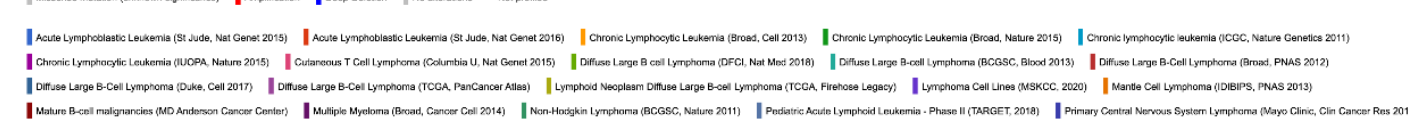

$\triangle 1$

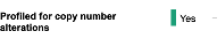

Inom - - 


\section{OESOPHAGAL CANCER}

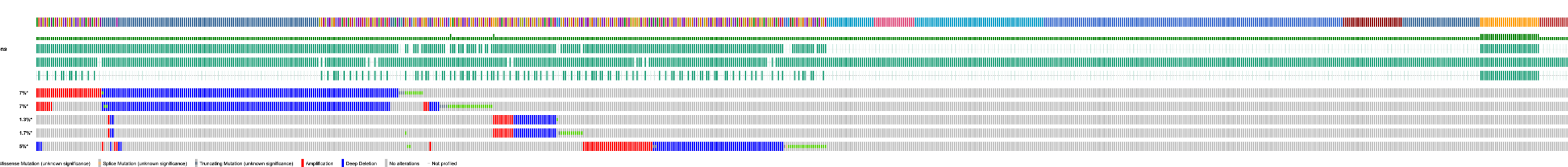

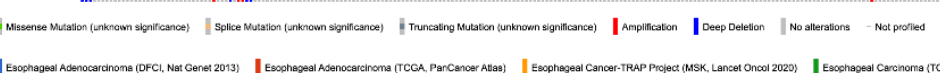

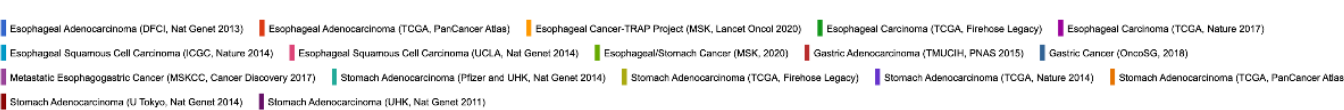

I somarastater

$=-1$

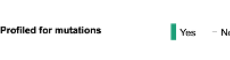




\section{OTHER CANCER TYPES}

Study of origin

\# Samples per P...

Profiled for co...

Profiled for mu....

Profiled for st...

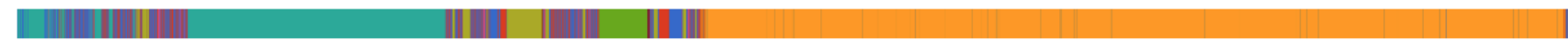

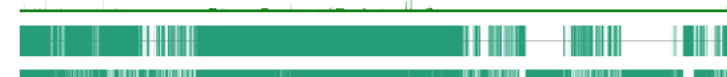

-

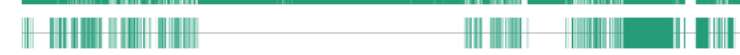

\section{III}

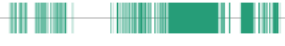

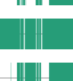

IIIII |||||||||||

$1.3 \% *$

${ }^{1.1 \% \%^{*}}$

$1.3 \% * \|$

$1.9 \% * \||||| \mid$

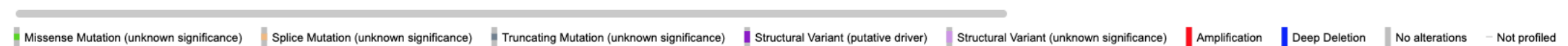

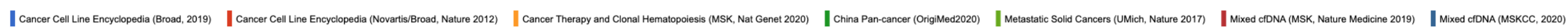

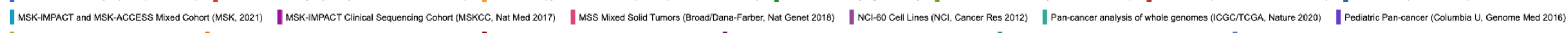

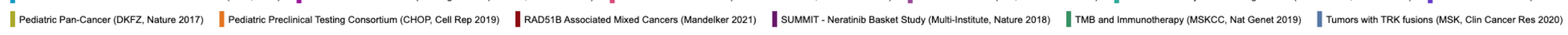

$0{ }^{14}$

| Yes - No

Iyes - No

| Yes - No 


\section{OVARIAN CANCER}

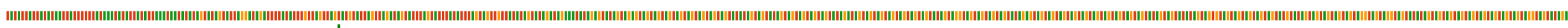

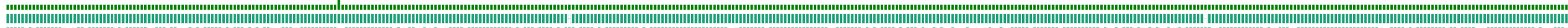

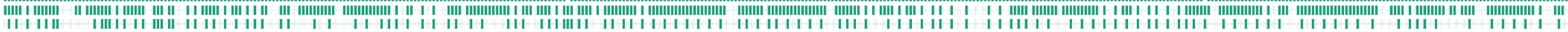

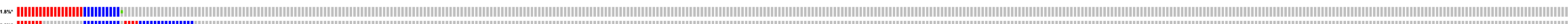
22x-

ง."

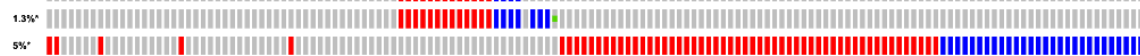

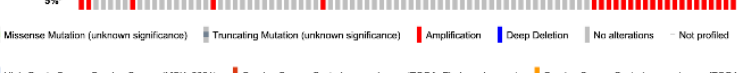

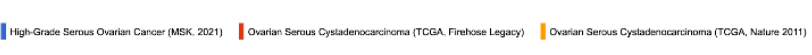

Iros - no

1mo

Ive - -

Tres $-n$ 


\section{PAN-CANCER STUDIES}

Study of origin

\# Samples per P...

Profiled for co...

Profiled for mu...

Profled for mu

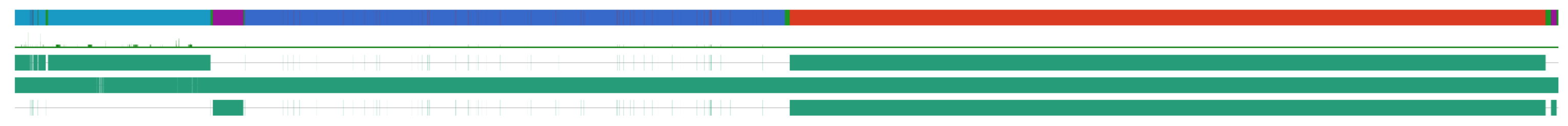

${ }^{0.7 \% *} \||||| \mid$

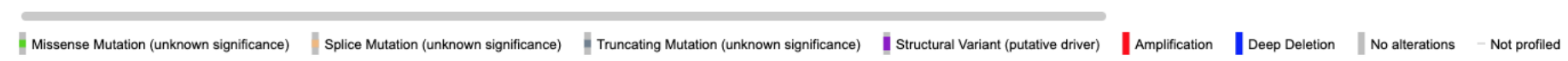

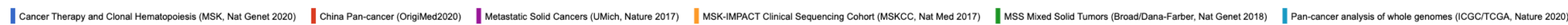

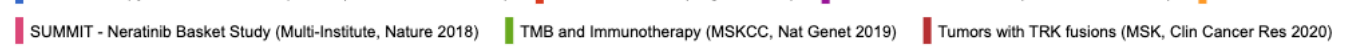

$\Lambda^{10}$

I Yes - No

IYes - No

IYes - No 


\section{PANCREAS}

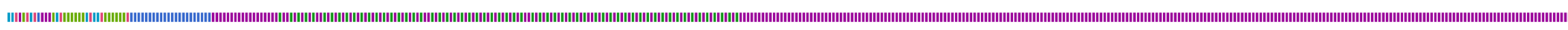

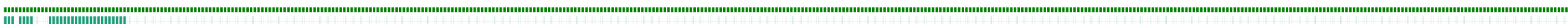

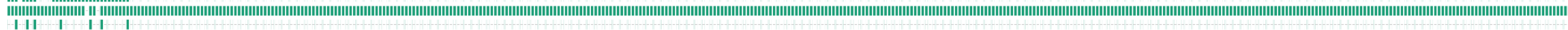

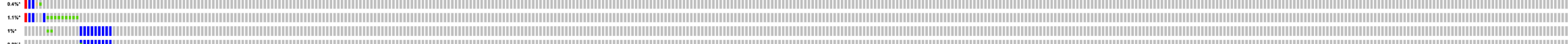

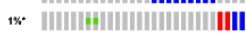

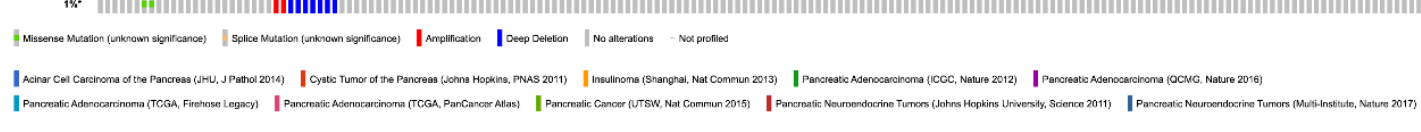

04

Irom -

Ire - -

Ires - - 


\section{PEDIATRIC CANCERS}

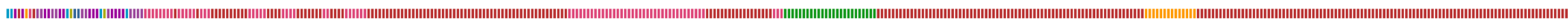

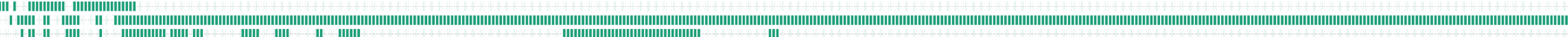
IIIII - IIII- II - IIIIII -

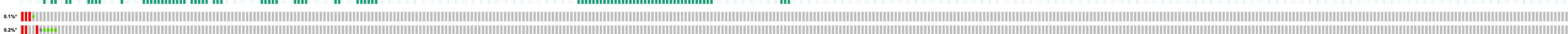
${ }^{202 x}$ ||||||||||||||||||||||||

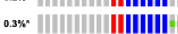

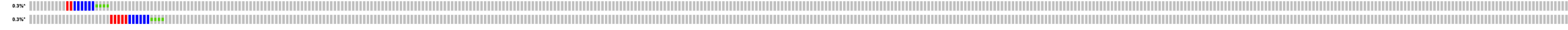

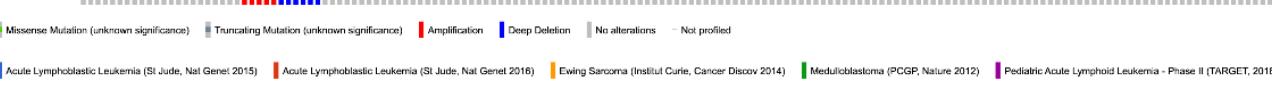

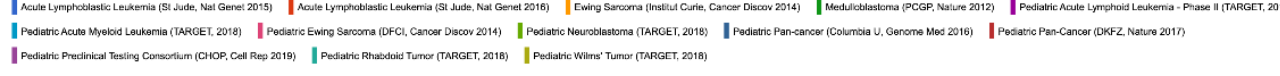

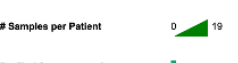

Prontere tor mutations

Ires - n 


\section{PERIFERAL NERVOUS SYSTEM CANCERS}

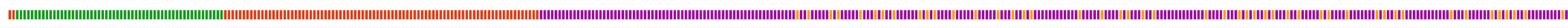
年

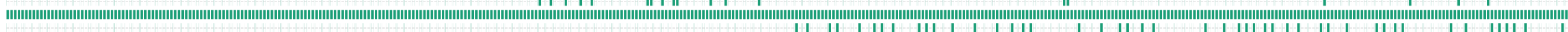

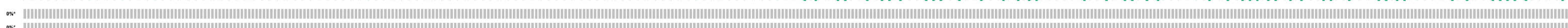

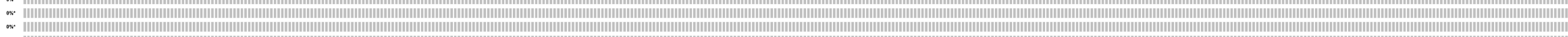

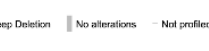

I matspant

I veo - No 


\section{PLEURA}

Study of origin

Profiled for copy number alterations

Profiled for mutations

Profiled for structural variants

SAT1

NROB1

SAT2

SHBG

DMRT1

Genetic Alteratior

Study of origin

Profiled for copy number

alterations

Profiled for mutations

filed for structural variants

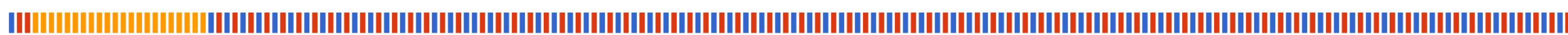

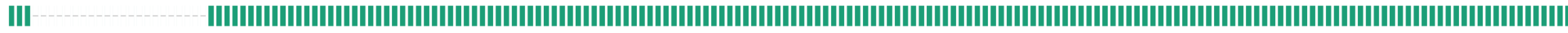

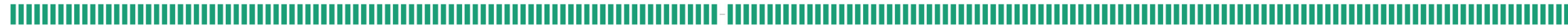
II

-

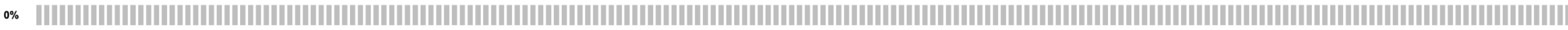

\%

๑

\%

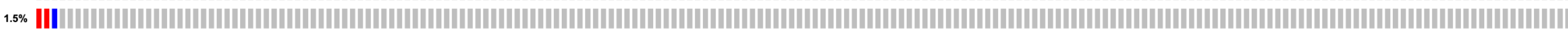
| Amplification | Deep Deletion || No atterations

I Mesothelioma (TCGA, Firehose Legacy) || Mesothelioma (TCGA, PanCancer Atlas) || Pleural Mesothelioma (NYU, Cancer Res 2015)

Yes - No

Yes - No

| Yes - No 


\section{PROSTRATE CANCER}

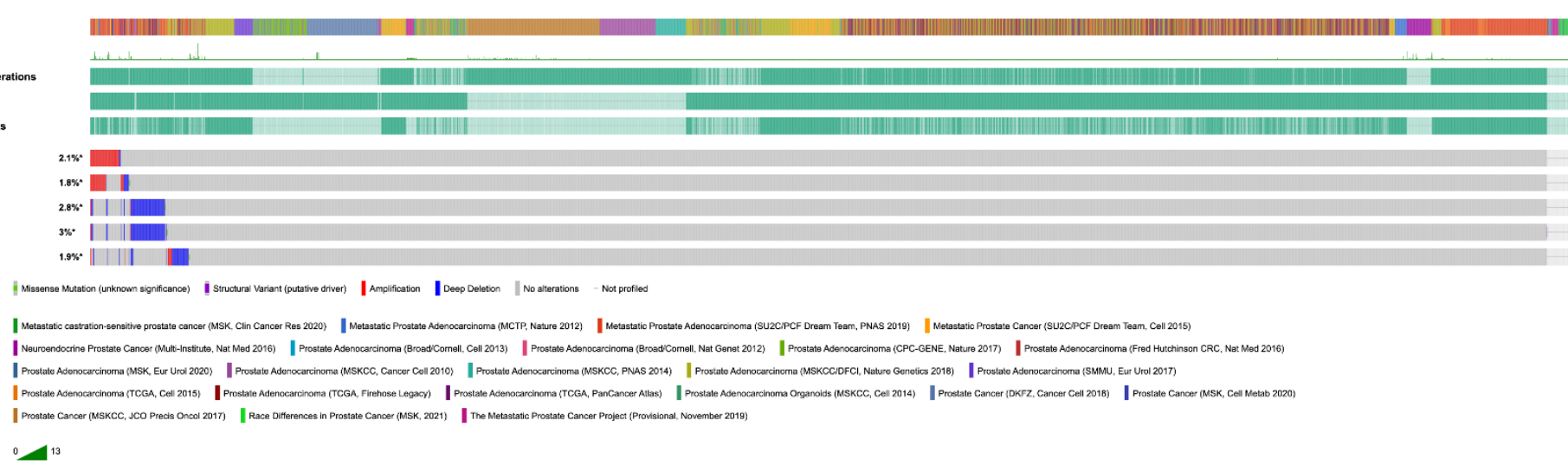




\section{AML / BLOOD CANCERS}

\begin{tabular}{|l|l|l|l|l|l|}
\hline Add Tracks - Sort r Mutations - New - Download - Q & $00 \%$ Q \\
\hline
\end{tabular}

Study of origin

Samples per $P$.

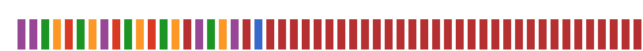

IIIIIIIIIIIIIIIIIIII

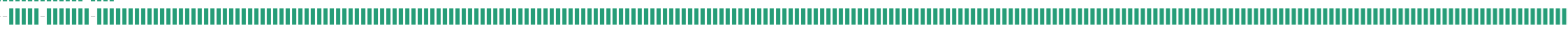

-II--II-II--||-- -

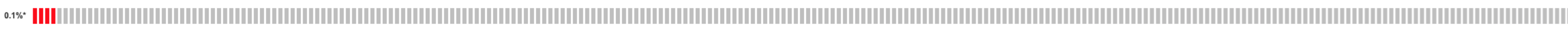

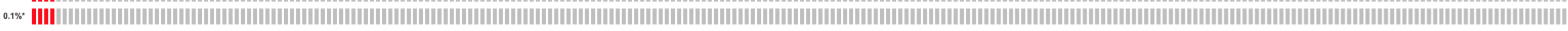

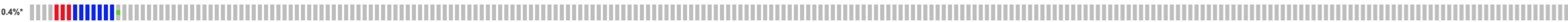

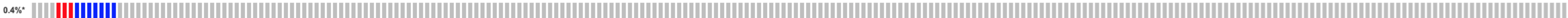

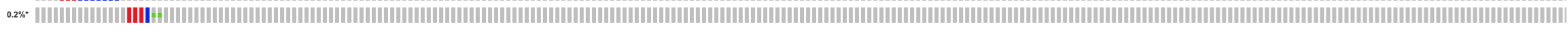

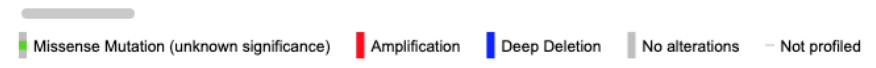

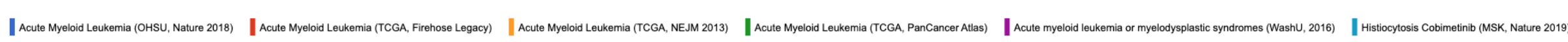

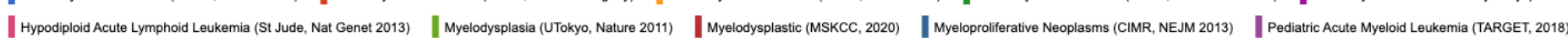

$\square^{6}$

IYes - No

| Yes - No

IYes - No 


\section{SKIN CANCERS}

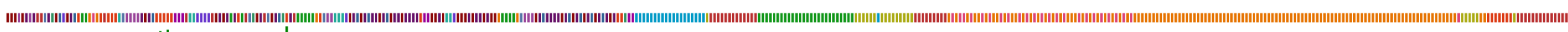

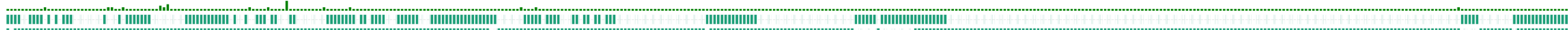

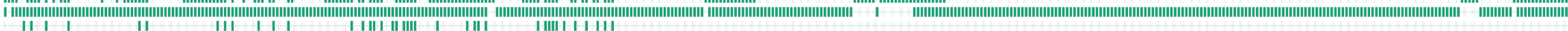

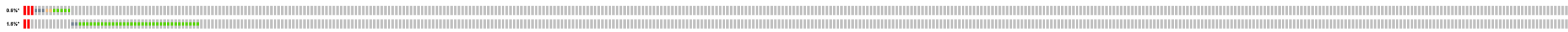

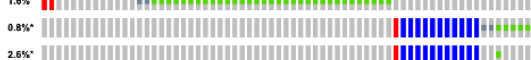

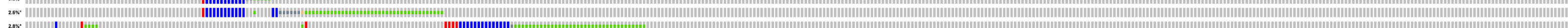

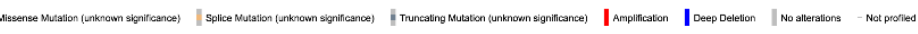

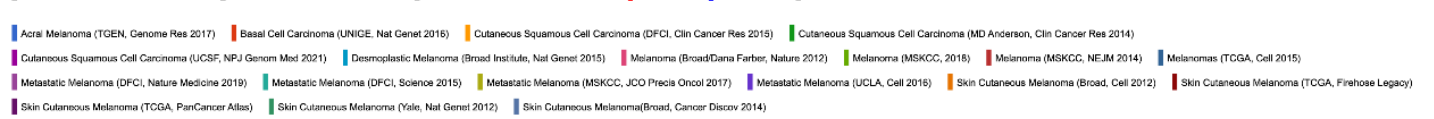

$\perp^{\circ}$

Ires - N

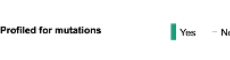




\section{TESTIS CANCERS}

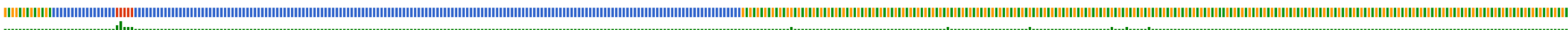

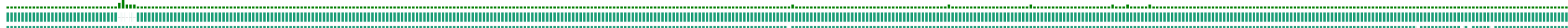

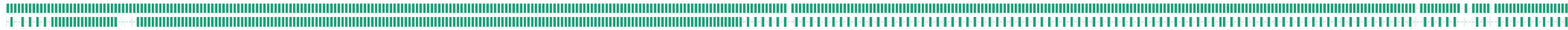

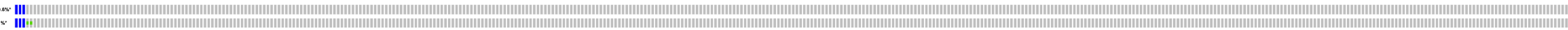

or" IIIIIIII

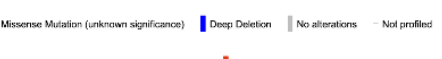

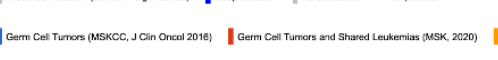

$\triangle^{5}$

Yros $-n^{-N}$

Inem -no 


\section{THYROID CANCER}

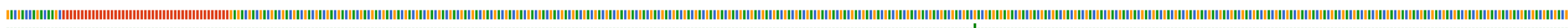

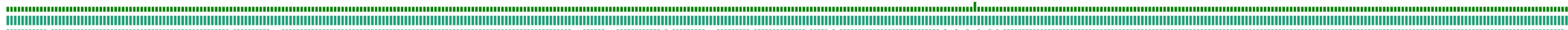

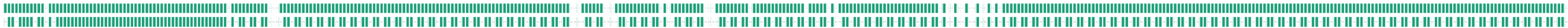

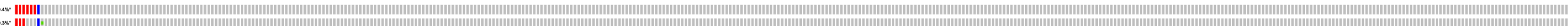

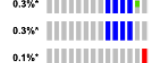

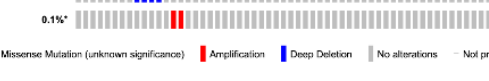

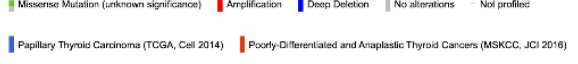

$0{ }^{2}$

Ires - No

Ives - - o

Inte 


\section{URETHRA}

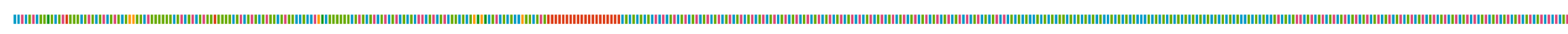

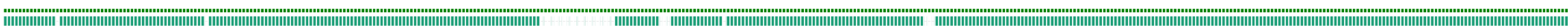

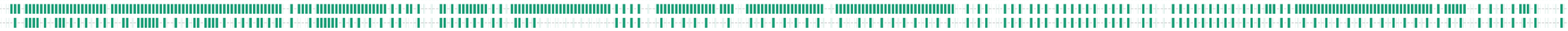
18s , งเต |

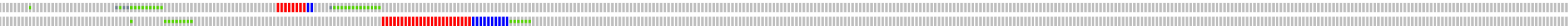

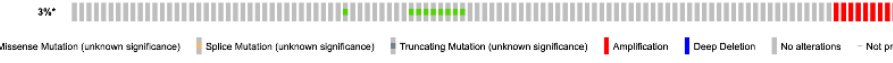

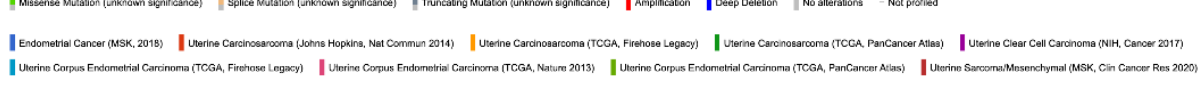

$\square^{3}$

Ins - no

Ins - -

Iros - - 